ORIGINAL ARTICLE

\title{
Human defensin 5 expression in intestinal metaplasia of the upper gastrointestinal tract
}

\author{
B Shen, E M Porter, E Reynoso, C Shen, D Ghosh, J T Connor, J Drazba, H K Rho, T L Gramlich, R Li, \\ A H Ormsby, M-S Sy, T Ganz, C L Bevins
}

J Clin Pathol 2005;58:687-694. doi: 10.1136/icp.2004.022426

See end of article for authors' affiliations

.

Correspondence to:

Dr C L Bevins, Department

of Medical Microbiology

and Immunology,

University of California

School of Medicine, One

Shields Avenue, Tupper

Hall, Room 3146, Davis,

California 95616, USA;

CLBevins@ucdavis.edu

Accepted for publication 8 December 2004

\begin{abstract}
Background: Upper gastrointestinal tract intestinal metaplasia (IM) is termed Barrett's oesophagus (BO) or gastric intestinal metaplasia (GIM), depending on its location. BO and GIM are associated with chemical exposure resulting from gastro-oesophageal reflux and chronic Helicobacter pylori infection, respectively. Paneth cells (PCs), characterised by cytoplasmic eosinophilic granules, are found in a subset of IM at these sites, but histology may not accurately detect them.

Aim: To determine human defensin 5 (HD5; an antimicrobial peptide produced by PCs) expression in BO and GIM, and to investigate its association with $H$ pylori infection.

Methods: Endoscopic biopsies from 33 patients with BO and 51 with GIM, and control tissues, were examined by routine histology and for $H$ pylori infection and HD5 mRNA and protein expression.

Results: In normal tissues, HD5 expression was specific for PCs in the small intestine. Five patients with BE and 42 with GIM expressed HD5, but few HD5 expressing cells in IM had the characteristic histological features of PCs. Most HD5 positive specimens were $\mathrm{H}$ pylori infected and most HD5 negative specimens were not infected.

Conclusions: HD5 immunohistochemistry was often positive in IM when PCs were absent by conventional histology. Thus, HD5 immunohistochemistry may be superior to histology for identifying metaplastic PCs and distinguishing GIM from BO. The higher frequency of HD5 expression in GIM than in BO is associated with a higher frequency of $H$ pylori infection, suggesting that in IM PCs may form part of the mucosal antibacterial response.
\end{abstract}

M etaplastic changes of the gastrointestinal (GI) epithelium are seen in many pathological states, and in some cases are considered an early sign of cancer development. Intestinal metaplasia (IM) can occur in the oesophagus (Barrett's oesophagus; $\mathrm{BO}$ ) and in the stomach, associated with atrophic gastritis (gastric intestinal metaplasia; GIM). The aetiology and pathogenesis of BO and GIM are presumably different. $\mathrm{BO}$ is probably a response to prolonged exposure of the mucosal surface to noxious chemicals present in gastric acid and bile salts, ${ }^{1}$ whereas GIM probably has an infectious aetiology, arising from chronic infection with Helicobacter pylori. ${ }^{2}$ The cancer risks associated with $\mathrm{BO}$ and GIM differ, and thus have an impact on the management of disease. $^{13-9}$ However, the distinction between these two metaplasias can be difficult by routine histology, especially in IM of the oesophagogastric junction (EGJ).

"The primary goal of our study was to evaluate a newly developed antihuman defensin 5 monoclonal antibody as a tool to detect Paneth cell metaplasia"

Histologically, a hallmark of IM is the presence of goblet cells outside of the small intestinal mucosa. IM can be further categorised into complete and incomplete forms, with the presence of Paneth cells (PCs) in the intestinalised epithelium being diagnostic for complete IM. ${ }^{10}{ }^{11}$ The complete form of IM is seen more often in GIM than in BO. ${ }^{12}{ }^{13}$ However, histologically evident PCs with characteristic eosinophilic cytoplasmic granules on haematoxylin and eosin (H\&E) staining are scarce in specimens of complete IM from either condition. ${ }^{14}{ }^{15}$

In the small intestine, PCs are secretory epithelial cells residing at the base of the crypts of Lieberkühn. ${ }^{16}$ Their prominent apical granules contain abundant antimicrobial polypeptides. These include $\alpha$ defensins, ${ }^{17-19}$ lysozyme, ${ }^{20}$ and secretory phospholipase $\mathrm{A}_{2}\left(\mathrm{sPLA}_{2}\right),{ }^{21}$ molecules that make an important contribution to host defences in the small intestine. ${ }^{22}{ }^{23}$ The $\alpha$ defensin HD5 is stored in PC secretory granules as a propeptide, ${ }^{19} 2425$ and is activated to a mature peptide after secretion by PC trypsin. ${ }^{19}$ HD5 has broad antimicrobial activity against various bacteria and the yeast Candida albicans in vitro. ${ }^{19} 26$ However, HD5 expression in pathological conditions, such as IM of the upper GI tract, has not been fully investigated. ${ }^{27-29}$

Helicobacter pylori is a Gram negative bacterium that commonly colonises the gastric mucosa, ${ }^{30}$ and is central to the pathogenesis of chronic gastritis, peptic ulcer disease, gastric adenocarcinoma, and a subset of gastric lymphomas. Several investigators have reported that the host response to $H$ pylori infection includes the induction of antimicrobial peptides - such as $\beta$ defensins and cathelicidins-in gastric epithelial cells. ${ }^{31-36}$ It is possible that, in IM, the presence of metaplastic PCs and HD5 expression, which are normally absent from the upper GI tract, are induced by the prolonged presence of $H$ pylori. Consistent with this notion, a recent study showed that metaplastic PCs in atrophic gastritis with GIM secrete HD5 and the authors proposed that the

Abbreviations: aa, amino acids; $\mathrm{BO}$, Barrett's oesophagus; $\mathrm{Cl}$, confidence interval; EGJ, oesophagogastric junction; ELISA, enzyme linked immunosorbent assay; GERD, gastro-oesophageal reflux disease; $\mathrm{Gl}$, gastrointestinal; GIM, gastric intestinal metaplasia; HD5, human defensin 5; H\&E, haematoxylin and eosin; IM, intestinal metaplasia; OR, odds ratio; PBS, phosphate buffered saline; $P C R$, polymerase chain reaction; $r$, recombinant; $R T$, reverse transcription; $\mathrm{sPLA}_{2}$, secretory phospholipase $\mathrm{A}_{2} ; \mathrm{PC}$, Paneth cells 
microbicidal activity of this peptide may serve to clear $H$ pylori from this site. ${ }^{28}$

Although PCs appear to be involved in various chronic gastrointestinal diseases, tools to study PCs have been limited and the role of these cells has not been fully investigated. The primary goal of our study was to evaluate a newly developed HD5 monoclonal antibody as a tool to detect PC metaplasia. This reagent allowed us to determine with high sensitivity the relative prevalence of HD5 expression between anatomical locations of IM (BO $v$ GIM), and to compare the frequency of HD5 expression in the presence or absence of $H$ pylori infection.

\section{PATIENTS AND METHODS}

The study protocol was approved by the institutional review board of the Cleveland Clinic Foundation, Cleveland, Ohio, USA, and the clinical, education, and research committee of Qidong City Hospital, Jiangsu Province, China.

\section{Patient specimens}

Endoscopic biopsy specimens from the normal oesophagus, stomach, small intestine, and colon, and BO and GIM specimens were studied for HD5 mRNA and the HD5 peptide by means of reverse transcriptase polymerase chain reaction (RT-PCR), northern and western blotting, immunohistochemistry, and confocal immunofluorescence microscopy. Specimens were obtained from 33 white patients with $\mathrm{BO}$ at the Cleveland Clinic Foundation and 51 Chinese patients with IM of the distal stomach and atrophic gastritis at the Qidong City Hospital. Exclusion criteria were short segment BO $(<3 \mathrm{~cm})$, IM at the EGJ, and dysplasia associated with IM. Goblet cell metaplasia was verified with the Alcian blue and periodic acid Schiff stains. Helicobacter pylori status was documented based on the CLO test (Delta West, Bentley, Western Australia) or Giemsa staining of an antral mucosa biopsy.

Ideally, the same ethnic population with $\mathrm{BO}$ and GIM should be studied and compared. However, BO is not common in Chinese populations where $H$ pylori infection, atrophic gastritis, GIM, and gastric cancer are common, and conversely GIM is rare in white populations where $\mathrm{BO}$ is common. We searched endoscopic reports and archival specimens from upper endoscopy at Qidong City Hospital in China, during the period 1990 to 2000, and found no patients diagnosed with BO. In contrast, despite its large digestive disease service, white patients with GIM are rare at the Cleveland Clinic, Ohio, USA. Therefore, the current prospective study compares $\mathrm{BO}$ and GIM in different racial populations. To overcome the patient selection bias, a baseline of HD5 expression in the oesophagus and stomach was established in normal adults of the corresponding ethnic population. We compared HD5 expression between BO and the normal oesophagus in the white population, and between
GIM and the normal stomach in the Chinese population. Five white patients with normal endoscopic and histological results from routine upper endoscopy for dyspepsia symptoms were included in our study as healthy controls for the BO group. Sixteen Chinese patients with normal endoscopic and histological results from routine upper endoscopy for the evaluation of GI symptoms served as ethnically matched controls for the GIM group. The H pylori infection status in these patients was documented based on CLO tests or Giemsa staining of antral mucosa biopsies.

\section{HD5 monoclonal antibodies}

A single step coupling protocol ${ }^{37}$ was used to conjugate recombinant proHD $5^{17}$ to ovalbumin for the immunisation of mice. ProHD5 (3 mg) was dissolved in $60 \mu \mathrm{l}$ of $0.01 \%$ acetic acid, further diluted with phosphate buffered saline (PBS) to $5 \mathrm{mg} / \mathrm{ml}$, and then admixed with $2 \mathrm{mg}$ of ovalbumin (Sigma, St Louis, Missouri, USA) in $0.4 \mathrm{ml}$ of PBS. Glutaraldehyde ( $1 \mathrm{ml}$ of $0.2 \%$ ) was added and the resulting mixture was stirred for one hour at $22^{\circ} \mathrm{C}$. Glycine in PBS was then added (200mM final concentration) to quench the reaction. The mixture was then dialysed against PBS (SpectraPor dialysis membrane, molecular weight cutoff $3.5 \mathrm{kDa}$ ), and used for routine monoclonal antibody production.

The reactivity of the monoclonal antibody 8C8 (ascites) was evaluated by western blotting, dot blotting, and enzyme linked immunosorbent assay (ELISA). Western blot analysis of small intestinal tissue extracts showed that 8C8 detected the same HD5 bands as the well characterised rabbit polyclonal antiserum, ${ }^{17} 1924$ and there was no crossreactivity with bands corresponding to HD6, lysozyme, or sPLA 2 (D Ghosh et al, unpublished data, 2002). Unless stated otherwise, all peptide antigens were recombinant peptides purified from baculovirus infected Hi5 cell culture supernatants, ${ }^{17}$ with and without subsequent in vitro cleavage with bovine trypsin. ${ }^{19}$ For dot blot analysis, peptides were adjusted to $10 \mu \mathrm{g} / \mathrm{ml}$ in $0.01 \%$ acetic acid, serially diluted, and $5 \mu \mathrm{l}$ of each dilution was applied to Immobilon PSQ membranes (MilliPore, Billerica, Massachusetts, USA). After 30 minutes of incubation at $4^{\circ} \mathrm{C}$ in a humid chamber, peptides were fixed to the membrane in $0.05 \%$ glutaraldehyde in Tris buffered saline, followed by a five minute wash in the same buffer. For protein staining, one membrane was incubated overnight at $22^{\circ} \mathrm{C}$ in $1 / 40$ diluted Coomassie blue and air dried. For immunoreactivity, a second membrane was processed as described previously using polyclonal rabbit anti-recombinant HD5 (anti-rHD5; 1/2000 dilution), anti-proHD5 (1/2000 dilution), and monoclonal anti-proHD5 clone 8C8 (mouse ascites; 1/1000 dilution), with alkaline phosphatase conjugated goat antirabbit IgG or goat antimouse IgG and the secondary antibody. ${ }^{38}$

For ELISA, all incubations were performed at $22^{\circ} \mathrm{C}$ using Fluoro Nunc MaxiSorp (Nunc, Rochester, New York, USA)

Table 1 Demographics

\begin{tabular}{|c|c|c|c|c|}
\hline & \multicolumn{2}{|c|}{ Oesophagus group } & \multicolumn{2}{|c|}{ Stomach group } \\
\hline & $\mathrm{BO}(n=33)$ & Controls $(n=5)$ & $\mathrm{GIM}(n=51)$ & Controls $(n=16)$ \\
\hline Mean age (SD) & $55.2(9.6)$ & $57.4(10.5)$ & $58.7(12.1)$ & $56.6(9.4)$ \\
\hline Male & $29(88 \%)$ & $5(100 \%)$ & $36(71 \%)$ & $11(68.8 \%)$ \\
\hline GERD symptoms & 31 (94\%) & 0 & $4(8 \%)$ & 0 \\
\hline Hiatal hernia & $27(82 \%)$ & $1(20 \%)$ & $2(4 \%)$ & $1(6.3 \%)$ \\
\hline Smoking & $18(55 \%)$ & $1(20 \%)$ & $32(63 \%)$ & $9(56.3 \%)$ \\
\hline Helicobacter pylori & $3 / 11(27 \%)$ & 0 & $44(86 \%)$ & 0 \\
\hline
\end{tabular}

The differences between the $B O$ and the GIM groups were significant in terms of GERD symptoms $(p<0.0001$ ), evidence of hiatal hernia ( $p<0.0001$ ), smoking $(p=0.45)$, and presence of $H$ pylori $(p<0.0001)$, but not for age or sex.

BO, Barrett's oesophagus; GERD, gastro-oesophageal reflux disease; GIM, gastric intestinal metaplasia. 

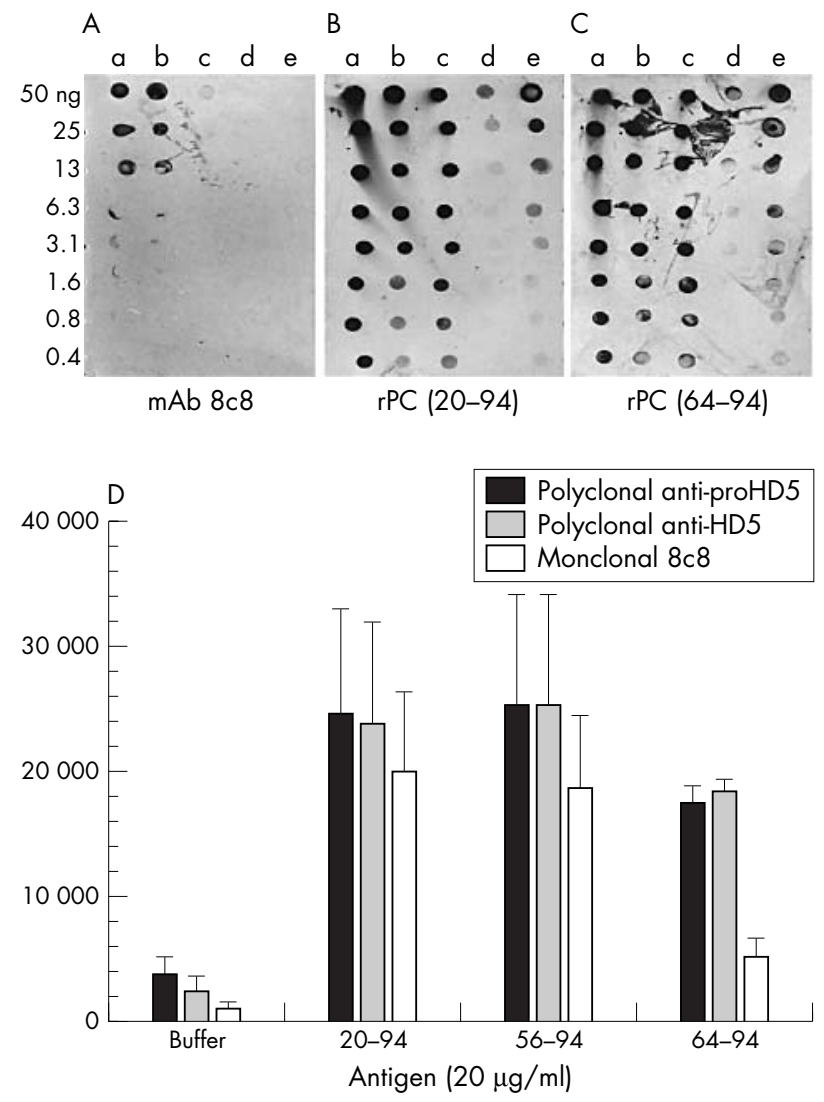

Figure 1 (A) Dot blot analysis of antibody detection of human defensin 5 (HD5) peptides. HD5 peptides were serially diluted in $0.01 \%$ acetic acid, spotted on to a membrane $(0.4-50 \mathrm{ng} / \mathrm{spot})$, and tested for reactivity with monoclonal antibody $8 \mathrm{C} 8$ (mAb $8 \mathrm{C} 8 ; 1 / 1000$ dilution) and (B, C) polyclonal HD5 antisera (1/2000 dilution) - polyclonal rabbit antiserum generated with recombinant proHD5 (amino acids (aa) 2094; rPC (20-94)) and polyclonal rabbit antiserum generated with recombinant HD5 (rPC 64-94)..$^{17}$ a, HD5 aa 20-94 (proHD5); b, HD5 aa 36-9424 $c$, HD5 aa 56-94; d, HD5 aa 63-94; e, 0.01\% acetic acid. Similar results were obtained with 8C8 diluted 1/500 (data not shown). Control blots with another antimicrobial peptide (pig protegrin 1) or hen egg white lysozyme were negative (data not shown). (D) Enzyme linked immunosorbent assay results. HD5 coated plates were incubated with $1 /$ 2000 diluted rPC (20-94), rPC (64-94), and monoclonal 8C8, and binding of the primary antibodies was detected with horseradish peroxidase conjugated secondary antibodies and AmplexRed substrate The resulting relative fluorescence was quantified with a fluorimeter. Using one way ANOVA, the reactivity of $\mathrm{m} 8 \mathrm{C} 8$ with fully processed rHD5 (aa 64-94) was significantly reduced when compared with HD5 (aa 20-94) ( $p=0.014$ ) and with HD5 (aa 56-94) $(p=0.023)$.

flat bottom microtitre plates, and reaction volumes of $100 \mu \mathrm{l} /$ well. Plates were coated with peptides $(20 \mu \mathrm{g} / \mathrm{ml}$ in $0.1 \mathrm{M}$ sodium bicarbonate; $\mathrm{pH}$ 9.6) overnight, washed three times with PBS $(200 \mu \mathrm{l})$ containing $0.05 \%$ Tween 20, blocked for one hour with $2 \%$ non-fat milk powder in PBS, incubated for two hours with primary antibody (polyclonal rabbit antirHD5 and anti-proHD5 diluted 1/2000, mouse ascites of monoclonal anti-proHD5 clone 8C8 diluted 1/1000) in $0.2 \%$ non-fat milk powder in PBS, as above, incubated for two hours with horseradish peroxidase conjugated goat antirabbit IgG (Pierce, Rockfort, Illinois, USA) or goat anti-mouse IgG (Molecular Probes, Eugene, Oregon, USA) diluted 1/400 in $1 \%$ bovine serum albumin in PBS, washed three times with 0.05\% Tween 20 in PBS, and developed with AmplexRed reagent (Molecular Probes, Eugene, Oregon, USA; prepared according to the manufacturer's instructions) for 30 minutes in the dark and fluorescence was read on a fluorimeter
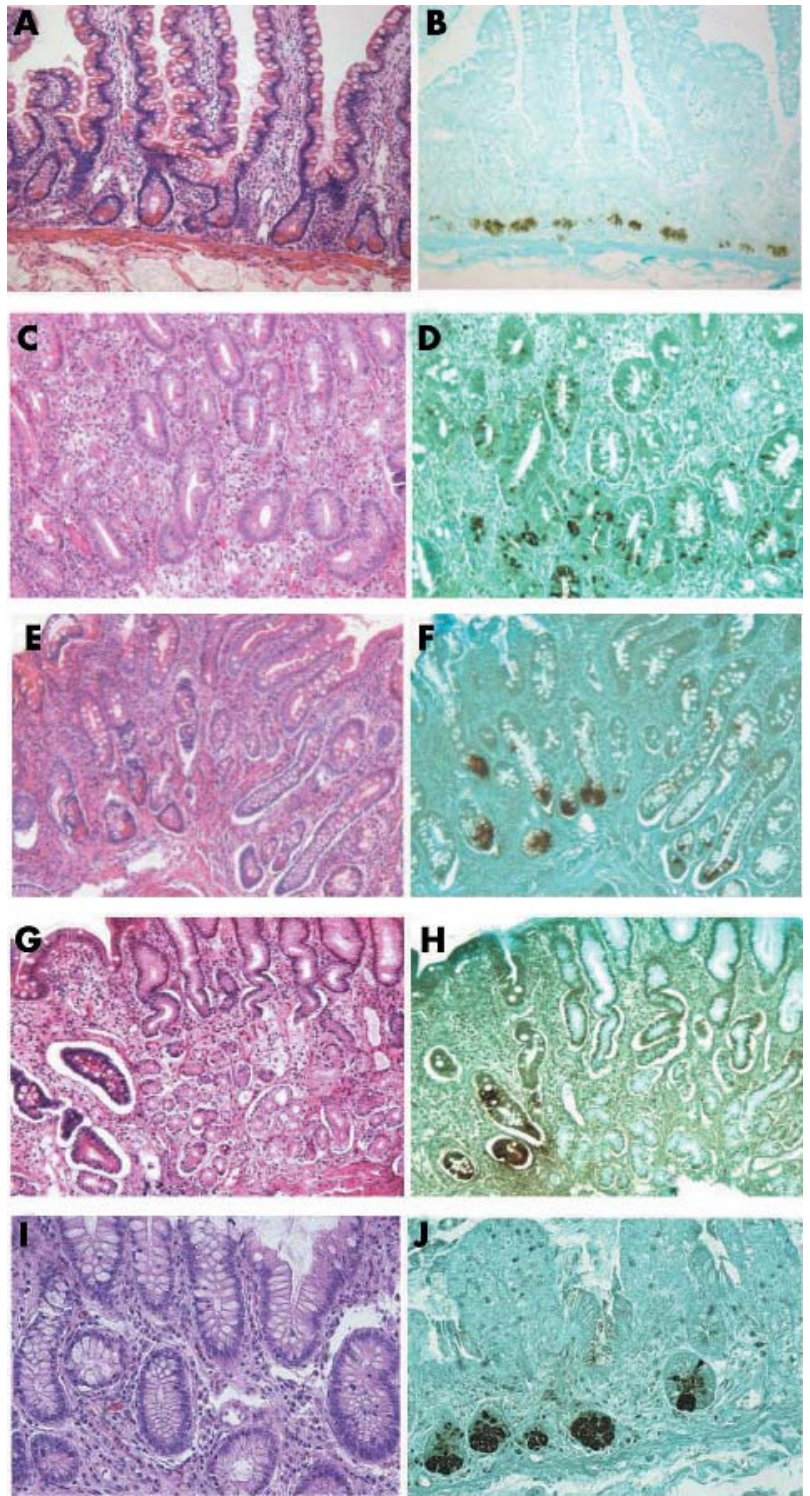

Figure 2 Detection of human defensin 5 (HD5) expression in gastrointestinal tissues by immunohistochemistry. Tissue sections were stained with the $8 \mathrm{C} 8$ monoclonal anti-HD5 antibody (B, D, F, H, and J), using a counterstain of light green. Parallel tissue sections were stained with haematoxylin and eosin (A, C, E, G, and I). The tissues were from the small intestine (A, B), Barrett's oesophagus with goblet cell metaplasia $(C, D)$, gastric intestinal metaplasia $(G I M)$ with goblet cells $(E$, $F), G I M$ at the border with normal gastric mucosa $(G, H)$, and ileal mucosa from ileal pouch after colectomy with an ileal pouch-anal anastomosis $(I, J)$. The pyramid shaped Paneth cells shown in (A) have characteristic eosinophilic secretory granules when viewed at higher power, but few or no eosinophilic granules are detectable in C, E, G, or $\mathrm{H}$.

(Geminix EM; Molecular Devices, Sunnyvale, California, USA) at $550 \mathrm{~nm}$ excitation/590 nm emission, with a cutoff at $590 \mathrm{~nm}$.

\section{Analysis of HD5 mRNA of normal and IM tissue samples}

The expression of HD5, lysozyme, and SPLA $_{2}$ mRNA in tissues along the GI tract was determined by northern blot analysis, as described previously. ${ }^{19}{ }^{39}$ A northern blot filter of RNA from healthy tissues (MTN blot; Clontech, Palo Alto, California, USA) was incubated with oligonucleotide hybridisation probes (Biosource International, Camarillo, California, 
USA), as follows: HD5 (HSIA-309a), ${ }^{39}$ lysozyme (5'-TGC ACAAGCTACAGCATCAGCGATGTTATCTTGCAGC-3'), sPLA

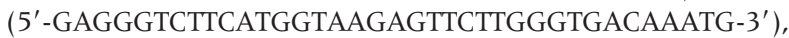
and glyceraldehyde 3-phosphate dehydrogenase (G3PDH-la $\left.{ }^{19}\right)$, using the experimental conditions described previously. ${ }^{19}$ After each analysis, the filter was stripped of oligonucleotide label and exposed to film to ensure that there was no residual signal.

Total RNA from the small intestine and IM tissue was isolated by the method of Chirgwin et al. ${ }^{40}$ cDNA was synthesised using a modified oligo-dT primer (marathon cDNA synthesis primer; Clontech) and commercial reagents (InVitrogen, Carlsbad, California, USA). The resulting cDNA product was used as a template in a PCR with HD5 oligonucleotide primers HD5-1362s (5'-TCCACTCCTGCTCT CCCTCC-3') and HD5-2698a (5'-TGAATCTTGCACTGCTTTG GTTTC-3'). PCR amplification was performed using the following conditions: $94^{\circ} \mathrm{C}$ for 25 seconds, then 34 cycles of $58^{\circ} \mathrm{C}$ for 30 seconds, $72^{\circ} \mathrm{C}$ for one minute, and $94^{\circ} \mathrm{C}$ for 25 seconds, with a final elongation of $72^{\circ} \mathrm{C}$ for five minutes $(0.2 \mu \mathrm{M}$ primer concentration; $10 \mathrm{mM}$ Tris/HCl $(\mathrm{pH} 8.3)$, $50 \mathrm{mM} \mathrm{KCl}, 1.5 \mathrm{mM} \mathrm{MgCl}_{2}$, and $0.2 \mu \mathrm{M} \mathrm{dNTP}$ ). The PCR products were verified by Southern blot hybridisation using a specific HD5 probe (HD5-309a) ${ }^{39}$ and by direct sequence analysis.
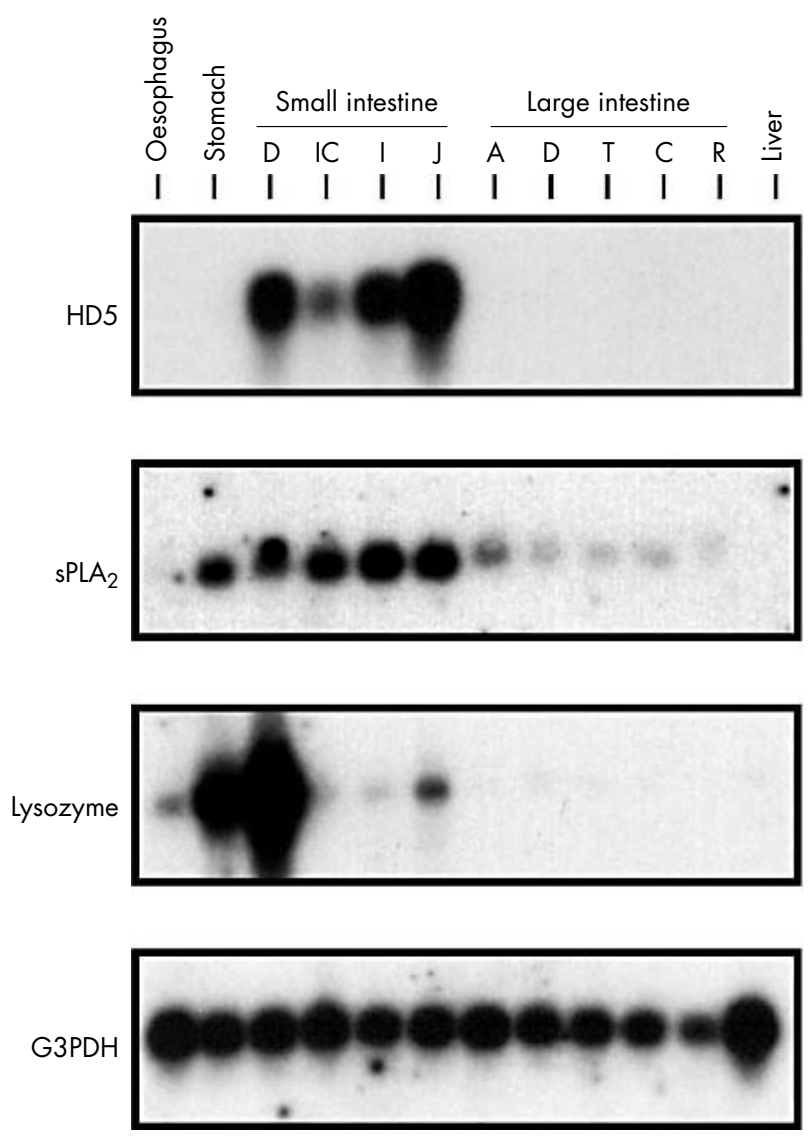

Figure 3 Northern blot analysis of antimicrobial peptide expression in the gastrointestinal tract. RNA from adult human non-diseased gastrointestinal tissues was analysed using probes for human defensin 5 (HD5), lysozyme, secretory phospholipase $A_{2}\left(s^{P} A_{2}\right)$, and glyceraldehyde-3-phosphate dehydrogenase (G3PDH). Abbreviations for small intestine: $D$, duodenum; IC, ileocaecum; I, ileum; J, jejunum; Abbreviations for large intestine: $A$, ascending; $D$, descending; $T$, transverse; $C$, caecum; $R$, rectum. The autoradiographic exposure was three days with an intensifying screen at $-80^{\circ} \mathrm{C}$.

\section{HD5 immunohistochemistry}

All tissue specimens were fixed in 3.7\% paraformaldehyde in PBS, which has been shown to be suitable for preserving intracytoplasmic granules in PCs. ${ }^{41}$ Paraffin wax embedded, $5 \mu \mathrm{m}$ thick tissue sections (dewaxed, treated with peroxide, and blocked as described previously ${ }^{19}$ ) were incubated overnight at $4^{\circ} \mathrm{C}$ with a $1 / 6000$ dilution of the mouse anti-HD5 monoclonal antibody (8C8), and staining was performed using Vectastain Elite ABC kit (Vector Laboratories, Burlingame, California, USA).

BO and GIM specimens were included for evaluation of HD5 immunostaining if they complied with the following criteria: (1) correct orientation of the biopsy specimen with the superficial glandular mucosa clearly delineated from underlying glandular mucosa; (2) IM confirmed on serial sections by the presence of glandular mucosa with unequivocal goblet cell morphology and both superficial and deep glands seen on H\&E and Alcian blue/periodic acid Schiff staining. The presence of immunoreactivity in five or more crypt cells for each low power field was considered positive.

\section{Fluorescent immunohistochemistry and confocal imaging of HD5 and lysozyme}

Paraffin wax embedded BO and GIM biopsy tissues were dewaxed, rehydrated, and then subjected to antigen retrieval, as described previously. ${ }^{19}$ The tissue sections were blocked with $0.15 \%$ horse serum in PBS for 20 minutes and incubated at $4^{\circ} \mathrm{C}$ overnight with the monoclonal mouse antibody to HD5 (clone 8C8; 1/6000 dilution) and a polyclonal rabbit antiserum to lysozyme at a dilution of 1/200 (Biogenex, San Ramon, California, USA). Biotinylated antimouse IgG/Alexa Fluor 568 conjugated streptavidin (red) and Alexa Fluor 488 conjugated antirabbit IgG (green) were used for immunodetection, and confocal images were obtained as described previously. ${ }^{19}$

\section{Western blot analysis of HD5}

Tissue specimens (3-7 mg wet weight) were placed in ice cold acetic acid (1/10 wt/vol) and immediately homogenised in the presence of protease inhibitors, as described previously. ${ }^{19}$ Samples $(30 \mu \mathrm{g} / \mathrm{lane})$ were resolved by $12.5 \%$ acid urea polyacrylamide gel electrophoresis, electroblotted on to a $0.2 \mu \mathrm{m}$ PVDF membrane, and analysed using a polyclonal rabbit anti-HD5 antibody and chemiluminescence detection. ${ }^{17} 19$

\section{Statistical analysis}

Descriptive statistics were presented as mean (l SD) for continuous variables or count (\%) for categorical variables; $t$ tests and $\chi^{2}$ tests were used to compare continuous variables and categorical variables, respectively. The ELISA data were analysed by one way ANOVA. All tests were performed at the $\alpha=0.05$ significance level. Logistic regression was performed to estimate odds ratios (OR) and 95\% confidence intervals (CI).

\section{RESULTS}

\section{Demographic and clinical data}

There were no significant differences in age, sex, and smoking history between the BO and GIM study groups; however, gastro-oesophageal reflux disease (GERD) symptoms were more common in the BO group. In addition, evidence of $H$ pylori infection was more prevalent in the GIM group (table 1).

\section{HD5 mRNA and peptide expression in normal and IM tissues}

The specificity of the monoclonal antibody for proHD5 (amino acids (aa) 20-94, the tissue form) and partially 
Table 2 HD5 expression in normal and intestinal metaplasia of the gastrointestinal tract

\begin{tabular}{|c|c|c|c|c|c|}
\hline & \multirow[b]{2}{*}{$\mathrm{N}$} & \multicolumn{2}{|c|}{ HD5 immunostaining } & \multicolumn{2}{|c|}{ Helicobacter pylori infection } \\
\hline & & Positive & Negative & Positive & Negative \\
\hline \multicolumn{6}{|l|}{ Tissues with IM } \\
\hline $\mathrm{BO}$ & 33 & $5(15 \%)$ & $28(85 \%)$ & $3(27 \%)$ & $8(73 \%)$ \\
\hline GIM & 51 & $42(82 \%)$ & $9(18 \%)$ & $44(86 \%)$ & $7(14 \%)$ \\
\hline \multicolumn{6}{|l|}{ Tissues without IM } \\
\hline Oesophagus & 5 & 0 & $5(100 \%)$ & NA & NA \\
\hline Stomach & 16 & 0 & $16(100 \%)$ & $9(56 \%)$ & $7(44 \%)$ \\
\hline Small intestine & 20 & $20(100 \%)$ & 0 & NA & NA \\
\hline Colon & 20 & 0 & $20(100 \%)$ & NA & NA \\
\hline
\end{tabular}

processed HD5 (aa 36-94 and 56-94) and lack of recognition of the fully processed HD5 form (aa 63-94 and 64-94) was established by dot blot analysis and ELISA (fig 1). HD5 immunohistochemistry was performed with the monoclonal antibody on GI tract specimens from various anatomical locations (table 2). HD5 immunoreactivity was readily detected in all normal small intestinal specimens $(\mathrm{n}=20)$, but was absent in normal oesophagus, stomach, and colon specimens. The topographical location and morphology of HD5 stained cells in the small intestine corresponded to typical PCs in sequential H\&E stained tissue sections (fig 2A, $\mathrm{B})$. Northern blot analysis was used to detect the expression of mRNA encoding the PC antimicrobials lysozyme, sPLA and HD5 in non-diseased GI tissues (fig 3). Consistent with the immunohistochemical data, HD5 mRNA was detected only in the small intestine where PCs are normally located. In addition to the small intestine, lysozyme and sPLA $_{2}$ mRNA was also detected in the stomach and colon. This indicates that these antimicrobials are also found in cells other than PCs, and are not specific PC markers.

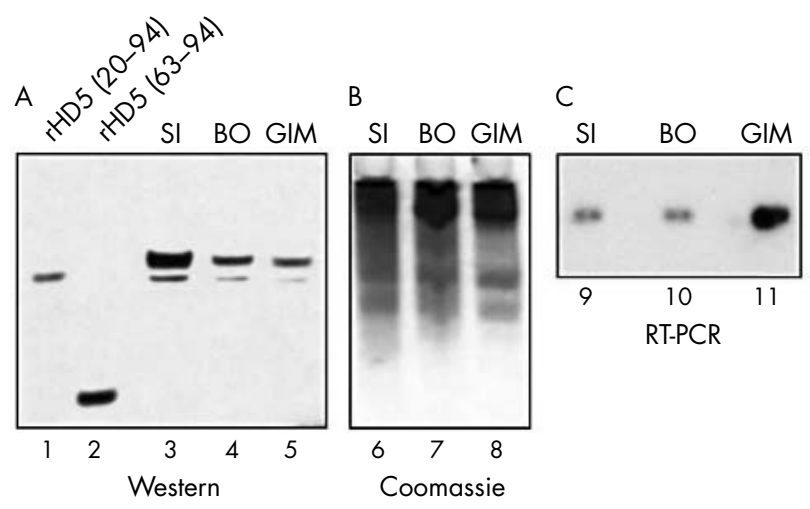

Figure 4 Western blot and reverse transcription polymerase chain reaction (RT-PCR) analyses of human defensin 5 (HD5) expression in the normal small intestine (SI), Barrett's oesophagus (BO), and gastric intestinal metaplasia (GIM). (A) Biopsy specimens, obtained by endoscopy of ileal tissue, BO, and GIM, along with recombinant (r) HD5 peptides, were resolved by $12.5 \%$ acid urea polyacrylamide gel electrophoresis (AU-PAGE), electroblotted on to PVDF, and probed with an anti-HD5 polyclonal antiserum. Quantities loaded in each lane were: tissues, extracts from $0.03 \mathrm{mg}$ of biopsy specimen; rHD5 (20-94), $20 \mathrm{ng}$; rHD5 (63-94), $20 \mathrm{ng}$. (B) Portions of the same samples used in (A) were resolved in parallel lanes of the $12.5 \%$ AU-PAGE, and either transferred to a PVDF membrane or stained with Coomassie blue to assess the amount of loading in each sample. (C) Total RNA was isolated from the biopsy specimens and subjected to RT-PCR amplification. A portion of each reaction was resolved by agarose gel electrophoresis, blotted on to a nylon membrane, and hybridised under high stringency conditions with a ${ }^{32} \mathrm{P}$ labelled HD5 probe. A second portion of the PCR product was subcloned into a plasmid vector for sequence analysis to confirm authentic HD5 amplification (not shown).
HD5 immunoreactivity was detected in 42 of the 51 patients with GIM, but in only five of the patients with BO (table $2 ; \mathrm{p}<0.001$ ). Using H\&E staining to detect PCs, 11 of the 51 GIM and none of the BO specimens had the complete form of IM. When considering HD5 expression as a possible marker for the diagnosis of GIM, the sensitivity and specificity based on these data are $82 \%$ and $84 \%$, respectively.

BO and GIM specimens that were positive for HD5 expression by immunohistochemistry were selected for comparative analysis with the normal small intestine. Using a polyclonal rabbit anti-HD5 antiserum that recognises all known HD5 forms, including fully processed HD5 (aa 63-94), HD5 derived from BO and GIM was indistinguishable from that of the normal small intestine by western analysis (fig 4A, B). RT-PCR analysis provided further evidence that this immunoreactivity was specific for the authentic HD5 peptide and that HD5 is synthesised by cells at the site of IM, rather than accumulating by cellular uptake and storage. The single product amplified with the HD5 specific primers co-migrated with the product from the small intestine (fig 4C), specifically hybridised with a HD5 probe (fig 4C), and had the correct HD5 nucleotide sequence (data not shown). Therefore, HD5 from the BO and GIM specimens appears to be identical to that seen in the normal small intestine.

\section{Association between HD5 expression and $H$ pylori infection in IM}

We found a significantly higher frequency of HD5 expression in GIM than in BO. Because there was a higher prevalence of $H$ pylori infection in the GIM samples (table 2), we investigated whether $H$ pylori infection and HD5 expression were related. Table 3 shows that HD5 staining was positive in 43 of 45 cases of $H$ pylori infection, but positive in only four of 17 cases without $H$ pylori infection. The OR for HD5 positivity, given evidence of $H$ pylori infection versus no such evidence was 69.9 (95\% CI, 11.5 to 425.7; p $<0.0001$; table 4). Subgroup analysis shows an OR of 82.0 (95\% CI, 7.3 to 922.0 ; $\mathrm{p}=0.0004)$ for GIM and 14.0 (95\% CI, 0.58 to 339.0; $\mathrm{p}=0.10$ ) for $\mathrm{BO}$ (table 4$)$.

Helicobacter pylori was detected in nine of the 16 Chinese patients with a normal gastric biopsy. The OR of $H$ pylori positivity for patients with GIM as compared with a normal gastric biopsy was 4.89 (95\% CI, 1.37 to 17.4), when comparing within the same ethnic population. No biopsy

Table 3 Association between human defensin 5 (HD5) expression and Helicobacter pylori infection

\begin{tabular}{lll}
\hline & H pylori positive & H pylori negative \\
\hline HD5 positive & $43(2 / 41)$ & $4(1 / 3)$ \\
HD5 negative & $2(1 / 1)$ & $13(7 / 6)$ \\
\hline
\end{tabular}

Counts shown as total (Barrett's oesophagus/gastric intestinal metaplasia). 
Table 4 Helicobacter pylori as a statistical risk factor for HD5

\begin{tabular}{llll}
\hline & OR & $95 \% \mathrm{Cl}$ & p Value \\
\hline Overall & 69.9 & 11.5 to 425.7 & $<0.0001$ \\
BO & 14.0 & 0.58 to 339.0 & 0.10 \\
GIM & 82.0 & 7.3 to 922.0 & 0.0004 \\
\hline
\end{tabular}

$\mathrm{BO}$, Barrett's oesophagus; $\mathrm{Cl}$, confidence interval; $\mathrm{GIM}$, gastric intestinal metaplasia; HD5, human defensin 5; OR, odds ratio.

specimen from the normal stomach showed HD5 immunoreactivity (table 2 ).

Morphological features of cells expressing HD5 in IM The cells staining positive for HD5 were typically, but not exclusively, found deep in the crypts of intestinalised mucosa in both $\mathrm{BO}$ (fig 2A, B) and GIM (fig 2E-H). These cells were most often pyramid shaped, similar to the PCs found in the small intestine. Surprisingly, the pyramid shaped cells expressing HD5 in these specimens mostly lacked the characteristic cytoplasmic eosinophilic granules normally identified by $\mathrm{H} \& \mathrm{E}$ staining in sequential sections (fig 2C$\mathrm{H})$, and thus were not recognisable as PCs using this stain. Only a small number of HD5 expressing cells (nine of 42 in GIM and none of five in $\mathrm{BO}$ ) had characteristic cytoplasmic eosinophilic granules. All PCs detected by H\&E staining were positive for HD5. To investigate whether lack of characteristic cytoplasmic eosinophilic granules in PCs is seen in other chronic disorders of the GI tract, we carried out HD5 immunohistochemistry of ileal tissue from pouches following colectomy surgery with ileal pouch-anal anastomosis with chronic inflammation and detected the same phenomenon (fig 2I, J). Thus, PCs may go undetected in some chronic inflammatory disorders of the GI tract.

To verify that the pyramid shaped HD5 expressing cells were PC variants, we used a double immunostaining technique for HD5 and another antimicrobial polypeptide expressed by PCs, which is less abundant-lysozyme. In BO and GIM specimens, the two molecules were colocalised (although lysozyme staining was weaker) (fig 5). This was seen both in cells with and without characteristic cytoplasmic eosinophilic granules (data not shown). This colocalisation supports the notion that cells expressing HD5 in BO and GIM are part of the PC lineage, even though they do not have cytoplasmic eosinophilic granules as assessed by $\mathrm{H} \& \mathrm{E}$ staining.

\section{DISCUSSION}

The presence of PCs has been used to categorise IM of the upper GI mucosa because in healthy individuals these cells are seen almost exclusively in the small intestine. However, the biological implications of their ectopic appearance are not understood, and a sensitive and specific marker for these cells
$\mathrm{BO}$
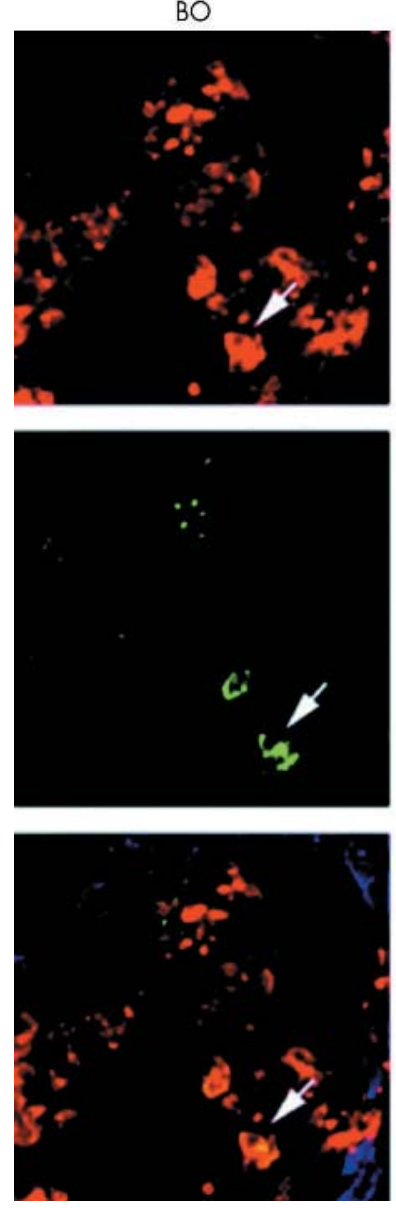

GIM
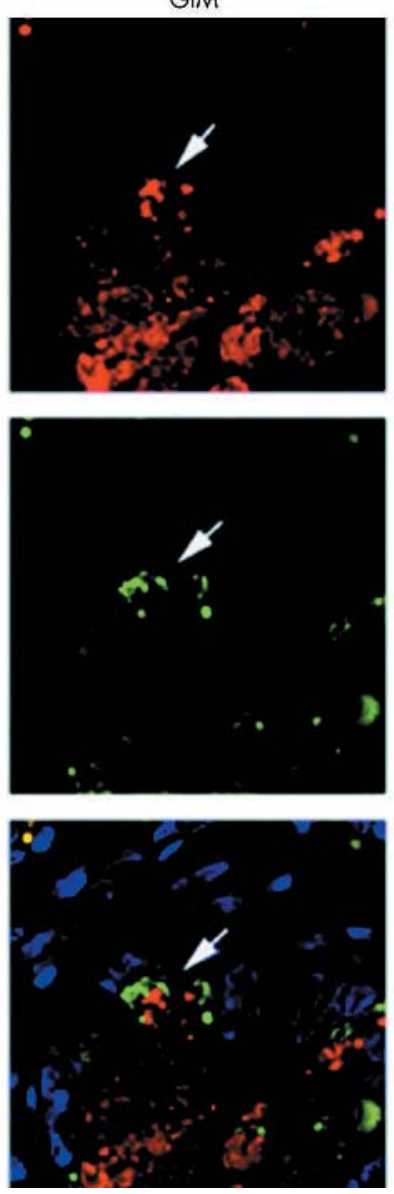
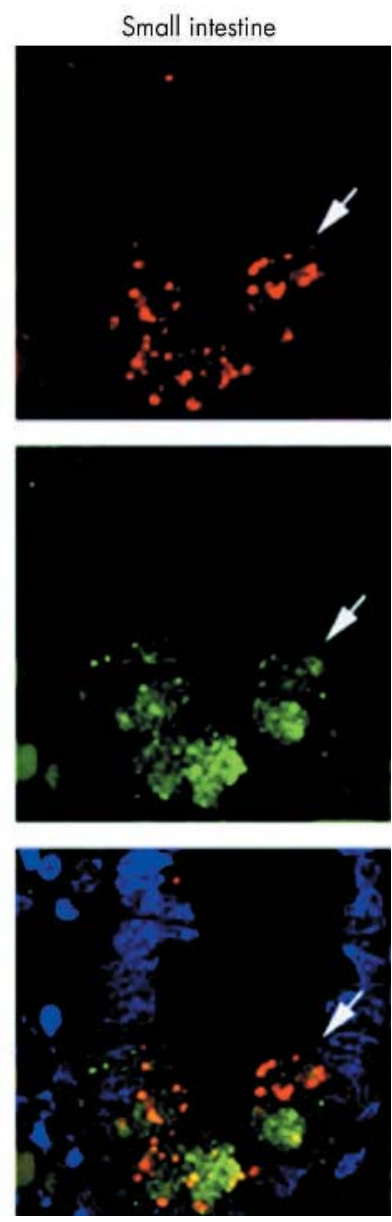

Figure 5 Colocalisation of human defensin 5 (HD5) and lysozyme in intestinal metaplasia of the upper gastrointestinal tract. Immunohistochemical colocalisation of HD5 and lysozyme in Barrett's oesophagus (BO), gastric intestinal metaplasia (GIM), and the distal small intestine. Tissue sections were incubated with monoclonal 8C8 anti-HD5 antibody and a polyclonal lysozyme specific antiserum. Biotinylated antimouse lgG/Alexa 568 (red) streptavidin and Alexa 488 (green) conjugated antirabbit lgG were used for immunodetection, respectively. The counterstain used was 4',6-diamidino2-phenylindole (DAPI). Arrows denote cells with colocalisation of HD5 (red) and lysozyme (green). 
is lacking. PCs are key elements of innate immunity in the intestinal tract. ${ }^{16} 1822234243$ Several antimicrobial polypeptides are abundantly expressed by PCs, including HD5, lysozyme, and $\mathrm{SPLA}_{2}$. All have been reported to be expressed also by other non-intestinal cell lineages outside of the intestinal tract. In addition, lysozyme and $\mathrm{sPLA}_{2}$ have been detected also within the GI tract in cells other than PCs and cannot serve as a specific biomarker for these cells. ${ }^{44-48}$ In contrast, in our analysis of normal GI tissues, HD5 mRNA and peptide expression was detected only in small intestinal PCs, and was absent in all other parts of the GI tract and in other intestinal cell lineages. Therefore, HD5 is a specific marker of PCs in the GI tract.

Using a specific anti-HD5 monoclonal antibody, we showed that HD5 was frequently expressed in IM of the upper GI tract. The HD5 expressing cells in BO and GIM were mainly located at the crypts of intestinalised epithelium. The HD5 expressing cells were pyramid shaped, similar to PCs in the small intestinal epithelium. However, most of the cells lacked the characteristic cytoplasmic granules of PCs in routine histology. HD5 immunohistochemistry indicated that 42 of the 51 GIM specimens and five of the 33 BO specimens had the complete form of IM. In contrast, H\&E analysis classified only 11 of the 51 GIM and none of the BO specimens as having the complete form of IM. Using confocal immunofluorescence, HD5 expressed in those cells was colocalised with lysozyme, another antimicrobial product of PCs, strongly supporting the notion that they are of the PC lineage. Because western blotting and mRNA analysis revealed authentic HD5 in IM tissues, some metaplastic PCs, although expressing HD5 and lysozyme, may contain fewer cationic granules than intestinal PCs, thus accounting for the lack of staining with the acidic dye eosin. These data indicate that HD5 immunohistochemistry is a more sensitive method of detecting PCs in $\mathrm{BO}$ and GIM than routine H\&E staining.

\section{"The sensitive and specific detection of Paneth cells by HD5 immunohistochemistry may be useful in determining the origin of intestinal metaplasia near the oesophago- gastric junction, with HD5 positive intestinal metaplasia supporting a gastric origin"}

HD5 immunohistochemistry corroborated the general observation that the mucosa of GIM is more frequently a complete form of IM with the presence of PCs, whereas that of $\mathrm{BO}$ is often characterised as incomplete IM. ${ }^{12}{ }^{13}$ In our investigation, we studied two distinct populations, BO from a white population with a high frequency of GERD and low frequency of $H$ pylori, and GIM from a Chinese population

Take home messages

- HD5 immunohistochemistry can detect Paneth cells (PCs), even when routine histology fails to demonstrate their characteristic cytoplasmic granules

- Thus, HD5 immunostaining may be useful for analysing intestinal metaplasia (IM) of the upper gastrointestinal tract

- The higher frequency of HD5 expression in gastric intestinal metaplasia than in Barrett's oesophagus is associated with a higher frequency of $H$ pylori infection, suggesting that in IM PCs may form part of the mucosal antibacterial response with infrequent GERD and a high frequency of $H$ pylori. Significant differences in HD5 expression were seen between the two groups. HD5 immunostaining was positive in five of the $33 \mathrm{BO}$ specimens, whereas it was positive in 42 of the 51 GIM specimens. IM in BO is associated with GERD, white ethnicity, male sex, negative $H$ pylori status, and increased risk for BO dysplasia or oesophageal adenocarcinoma. GIM lacks a sex or racial predilection and has a lower risk for the development of adenocarcinoma. ${ }^{35-8}$ It is important to identify the source of IM at the EGJ, because IM of the oesophagus (BO) has a different cancer risk, so that GIM and BO requires different endoscopic surveillance programmes. ${ }^{13-9}$ The sensitive and specific detection of PCs by HD5 immunohistochemistry may be useful in determining the origin of IM near the EGJ, with HD5 positive IM supporting a GIM origin. In a previous study from members of our group, ${ }^{99}$ the pattern of expression of cytokeratins 7 and 20 was also found to be useful in differentiating BO from GIM, and perhaps these assays could complement one another in this important differential diagnosis.

The mechanisms underlying the appearance of PC metaplasia are not understood. The results of our study support the hypothesis that in the upper GI tract the appearance of metaplastic PCs and HD5 expression might be induced by bacterial pathogens, such as $H$ pylori. We found differences in the frequency of $H$ pylori infection between the BO and GIM groups, with $H$ pylori infection being more common in GIM, where HD5 expression is also more prevalent. The difference in the prevalence of $H$ pylori infection between BO and GIM might explain the difference in frequency of HD5 expression and PC metaplasia between the two disease entities. Other investigators have reported similar findings. A recent study showed that metaplastic PCs in atrophic gastritis with GIM secrete HD5, ${ }^{28}$ and GIM including IM of the EGJ has been shown to be associated with a higher frequency of $H$ pylori infection than $\mathrm{BO} .{ }^{1}{ }^{7}$ In contrast, $H$ pylori infection is not implicated in the pathogenesis of $\mathrm{BO}$, and some authors have even speculated that it may play a protective role against the development of $\mathrm{BO}^{50-52}$ It is also possible that it is not the mere presence of $H$ pylori, but rather the ability of certain strains of $H$ pylori to elicit an inflammatory response, that is important for the development of PC metaplasia. Consistent with this notion, Forsberg et al showed that in coeliac disease there is a link between PC metaplasia and interferon $\gamma$ production by intraepithelial lymphocytes. ${ }^{53}$

In conclusion, HD5 immunohistochemistry detects PCs, even when routine histology fails to demonstrate their characteristic cytoplasmic granules, and thus may provide a powerful tool for the analysis of IM of the upper GI tract. The difference in the frequency of HD5 expression between BO and GIM may be the result of the difference in frequency of $H$ pylori infection between the two disease entities, and the appearance of metaplastic PCs in IM may reflect an adaptive change of the mucosa to increase innate immunity to noxious microbes.

\section{ACKNOWLEDGEMENTS}

The authors thank Dr R Desharnais for help with statistical analysis, Dr J Wehkamp for helpful discussions on the manuscript, and Ms J Lee for technical assistance. We acknowledge the valuable suggestions of the two anonymous reviewers of this manuscript. This work was partially supported by a research grant from the American College of Gastroenterology (BS), Minority Opportunities in Research Program Program (ER), and from The National Institutes of Health AI 32738 (CLB).

\section{Authors' affiliations}

B Shen, Department of Gastroenterology and Hepatology, The Cleveland Clinic Foundation, 9500 Euclid Avenue, Cleveland, $\mathrm{OH}$ 44195, USA 
E M Porter, E Reynoso, Department of Biological Sciences, California State University Los Angeles, 5151 State University Drive, Los Angeles, CA 90032, USA

T Ganz, Department of Medicine, David Geffen School of Medicine at UCLA, 10833 Le Conte Ave, Los Angeles, California 90095, USA

C Shen, Gastroendoscopy Unit, Qidong City Hospital, Qidong, Jiangsu Province, China 226200

D Ghosh, J Drazba, H K Rho, C L Bevins, The Lerner Research Institute, The Cleveland Clinic Foundation

J T Connor, Departments of Biostatistics and Epidemiology, The Cleveland Clinic Foundation

T L Gramlich, A H Ormsby, Department of Anatomic Pathology, The Cleveland Clinic Foundation

R Li, M-S Sy, Department of Pathology, Case Western Reserve University School of Medicine, 10900 Euclid Avenue Cleveland, OH 44106, USA

\section{REFERENCES}

1 Falk GW. Barrett's esophagus. Gastroenterology 2002;122:1569-91.

2 Goldblum JR, Richter JE, Vaezi $M$, et al. Helicobacter pylori infection, not gastroesophageal reflux, is the major cause of inflammation and intestinal metaplasia of gastric cardiac mucosa. Am J Gastroenterol 2002;97:302-11

3 Spechler SJ, Zorrogian JM, Antonioli DA, et al. Prevalence of metaplasia at the gastro-esophageal junction. Lancet 1994;344:1533-6.

4 Sharma P, Morales TG, Bhattachayya A, et al. Dysplasia in short segment Barrett's esophagus: a prospective 3-year follow-up. Am J Gastroenterol 1997;92:2012-16.

5 Trudgill NJ, Suvarna SK, Kapur KC, et al. Intestinal metaplasia at the squamocolumnar junction in patients attending for diagnostic endoscopy. Gut 1997:41:585-9.

6 Hackelsberger A, Gunther T, Schultze V, et al. Intestinal metaplasia at the gastro-oesophageal junction: Helicobacter pylori gastritis or gastrooesophageal reflux disease? Gut 1998;43:17-21.

7 Hirota WK, Loughney TM, Lazas DJ, et al. Specialized intestinal metaplasia, dysplasia, and cancer of the esophagus and esophagogastric junction: prevalence and clinical data. Gastroenterology 1999;1 16:277-85.

8 Morales TG, Camargo E, Bhattacharyya A, et al. Long-term follow-up of intestinal metaplasia of the gastric cardia. Am J Gastroenterol 2000:95: 1677-80.

9 Ormsby AH, Vaezi MF, Richter JE, et al. Cytokeratin immunoreactivity patterns in the diagnosis of short-segment Barrett's esophagus. Gastroenterology 2000;1 19:683-90.

10 Rubio CA, Sugano H, Kitagawa T. Intestinal metaplasia of the stomach in Swedish and Japanese patients without ulcers or carcinoma. Jpn J Cancer Res 1987;78:467-72

11 Rubio CA, Matthies M, Itabashi M, et al. Image quantitation of intestinal metaplasia in entire gastrectomy specimens from Swedish and Japanese patients. Jpn J Cancer Res 1996;87:711-17.

12 Silva S, Filipe MI, Pinho A. Variants of intestinal metaplasia in the evolution of chronic atrophic gastritis and gastric ulcer. A follow up study. Gut 1990;31:1097-104

13 van Sandick JW, van Lanschot JB, van Felius L, et al. Intestinal metaplasia of the esophagus or esophagogastric junction: evidence of distinct clinical, pathologic, and histochemical staining features. Am J Clin Pathol 2002;117:117-25.

14 Schriber DS, Apstein M, Hermos JA. Paneth cells in Barrett's esophagus. Gastroenterology 1978;74:1302-4.

15 Rubio CA, Porwit-McDonald A, Rodensjo $M$, et al. A method of quantitating Paneth cell metaplasia of the stomach by image analysis. Anal Quant Cytol Histol 1989;11:115-18.

16 Porter EM, Bevins CL, Ghosh D, et al. The multifaceted Paneth cell. Cell Mol Life Sci 2002;59:156-70.

17 Porter E, Liu L, Oren A, et al. Localization of human intestinal defensin 5 in Paneth cell granules. Infect Immun 1997;65:2389-95.

18 Ayabe T, Satchell DP, Wilson CL, et al. Secretion of microbicidal alphadefensins by intestinal Paneth cells in response to bacteria. Nat Immunol 2000;1:113-18.

19 Ghosh D, Porter EM, Shen B, et al. Paneth cell trypsin is the processing enzyme for human defensin-5. Nat Immunol 2002;3:583-90.

20 Peeters T, Vantrappen G. The Paneth cell: a source of intestinal lysozyme. Gut 1975;16:553-8.

21 Nevalainen TJ, Gronroos JM, Kallajoki M. Expression of group II phospholipase A2 in the human gastrointestinal tract. Lab lnvest 1995;72:201-8.

22 Wilson CL, Ouellette AJ, Satchell DP, et al. Regulation of intestinal alphadefensin activation by the metalloproteinase matrilysin in innate host defense. Science 1999;286:113-17.

23 Salzman NH, Ghosh D, Huttner KM, et al. Protection against enteric salmonellosis in transgenic mice expressing a human intestinal defensin. Nature 2003;422:522-6.
24 Porter EM, Poles MA, Lee JS, et al. Isolation of human intestinal defensins from ileal neobladder urine. FEBS Lett 1998;434:272-6.

25 Cunliffe RN, Rose FR, Keyte J, et al. Human defensin 5 is stored in precursor form in normal Paneth cells and is expressed by some villous epithelial cells and by metaplastic Paneth cells in the colon in inflammatory bowel disease. Gut 2001;48:176-85.

26 Porter $E$, van Dam E, Valore $E$, et al. Broad spectrum antimicrobial activity of human intestinal defensin 5. Infect Immun 1997;65:2396-401.

27 Inada K, Tanaka H, Nakanishi H, et al. Identification of Paneth cells in pyloric glands associated with gastric and intestinal mixed-type intestinal metaplasia of the human stomach. Virchows Arch 2001;439:14-20.

28 Ayabe T, Satoh T, Watari J, et al. Ectopic Paneth cells in intestinal metaplasia of human stomach are capable of clearing Helicobacter pylori by microbicidal secretion. Gastroenterology 2002;122:A70.

29 Wong WM, Stamp GW, Elia G, et al. Proliferative populations in intestinal metaplasia: evidence of deregulation in Paneth and goblet cells, but not endocrine cells. J Pathol 2000;190:107-13.

30 Suerbaum S, Michetti P. Helicobacter pylori infection. N Engl J Med 2002:347:1175-86

31 O'Neil DA, Cole SP, Martin-Porter E, et al. Regulation of human betadefensins by gastric epithelial cells in response to infection with Helicobacter pylori or stimulation with interleukin-1. Infect Immun 2000;68:5412-15.

32 Hamanaka $Y$, Nakashima $M$, Wada $A$, et al. Expression of human betadefensin 2 (hBD-2) in Helicobacter pylori induced gastritis: antibacterial effect of hBD-2 against Helicobacter pylori. Gut 2001;49:481-7.

33 Bajaj-Elliott M, Fedeli P, Smith GV, et al. Modulation of host antimicrobial peptide (beta-defensins 1 and 2) expression during gastritis. Gut 2002:51:356-61.

34 Hase K, Murakami M, limura M, et al. Expression of LL-37 by human gastric epithelial cells as a potential host defense mechanism against Helicobacter pylori. Gastroenterology 2003;125:1613-25.

35 George JT, Boughan PK, Karageorgiou H, et al. Host anti-microbial response to Helicobacter pylori infection. Mol Immunol 2003:40:451-6.

36 Wehkamp J, Schmidt K, Herrlinger KR, et al. Defensin pattern in chronic gastritis: HBD-2 is differentially expressed with respect to Helicobacter pylori status. J Clin Pathol 2003;56:352-7.

37 Harlow E, Lane D. Antibodies: a laboratory manual. Cold Spring Harbor, NY: Cold Spring Harbor Laboratory Press, 1988.

38 Hertz CJ, Wu Q, Porter EM, et al. Activation of Toll-like receptor 2 on human tracheobronchial epithelial cells induces the antimicrobial peptide human beta defensin-2. J Immunol 2003;171:6820-6.

39 Jones DE, Bevins CL. Paneth cells of the human small intestine express an antimicrobial peptide gene. J Biol Chem 1992;267:23216-25

40 Chirgwin JM, Pryzybyla AE, MacDonald RJ, et al. Isolation of biologically active ribonucleic acid from sources enriched in ribonuclease. Biochemistry 1979; 18:5294-9

41 Elmes ME, Jones JG, Stanton MR. Changes in the Paneth cell population of human small intestine assessed by image analysis of the secretory granule area. J Clin Pathol 1983;36:867-72.

42 Ouellette A, Bevins CL. Paneth cell defensins and innate immunity of the small bowel. Inflamm Bowel Dis 2001;7:43-50.

43 Cunliffe RN, Mahida YR. Expression and regulation of antimicrobial peptides in the gastrointestinal tract. J Leukoc Biol 2004;75:49-58.

44 Thompson AB, Bohling T, Payvandi F, et al. Lower respiratory tract lactoferrin and lysozyme arise primarily in the airways and are elevated in association with chronic bronchitis. J Lab Clin Med 1990;115:148-58.

45 Coutinho HB, Robalinho TI, Coutinho VB, et al. Immunocytochemical demonstration that human duodenal Brunner's glands may participate in intestinal defence. J Anat 1996;189:193-7.

46 Quayle AJ, Porter EM, Nussbaum AA, et al. Gene expression, immunolocalization and secretion of human defensin-5 in human female reproductive tract. Am J Pathol 1998;152:1247-58.

47 Qu XD, Lehrer RI. Secretory phospholipase A2 is the principal bactericide for staphylococci and other Gram-positive bacteria in human tears. Infect Immun 1998;66:2791-7

48 Chen FS, Scher DM, Clancy RM, et al. In vitro and in vivo activation of polymorphonuclear leukocytes in response to particulate debris. J Biomed Mater Res 1999;48:904-12.

49 Shen B, Ormsby AH, Shen C, et al. Cytokeratin expression patterns in noncardia, intestinal metaplasia-associated gastric adenocarcinoma: implication for the evaluation of intestinal metaplasia and tumors at the esophagogastric junction. Cancer 2002;94:820-31.

50 Lord RVN, Frommer DJ, Inder S, et al. Prevalence of Helicobacter pylori infection in 160 patients with Barrett's oesophagus or Barrett's adenocarcinoma. Aust N Z J Surg 2002;70:26-33.

51 El-Serag HB, Sonnenberg AG. Opposing time trends of peptic ulcer and reflux disease. Gut 1999;43:327-33.

52 Chow WH, Blaser MJ, Blot WJ, et al. An inverse relation between cagA+ strains of Helicobacter pylori infection and risk of esophageal and gastric cardia adenocarcinoma Cancer Res 1998:58:588-90.

53 Forsberg G, Fahlgren A, Horstedt $P$, et al. Presence of bacteria and innate immunity of intestinal epithelium in childhood celiac disease. Am J Gastroenterol 2004;99:894-904. 